\title{
Um olhar para as educadoras do campo a partir da Escola da Terra, do
}

\section{Pronacampo}

A look at the women rural educators from the land school action, from

Pronacampo

Una mirada a las mujeres educadoras rurales desde la acción de la escuela de la tierra de Pronacampo

Recebido: 18/01/2022 | Revisado: 22/01/2022 | Aceito: 25/01/2022 | Publicado: 26/01/2022

\author{
Silvana Barreto Oriente \\ ORCID: https://orcid.org/0000-0001-7957-0070 \\ Universidade Federal do Amazonas, Brasil \\ E-mail: silvanaboriente@gmail.com \\ Maria Isabel Alonso Alves \\ ORCID: https://orcid.org/0000-0002-2960-1200 \\ Universidade Federal do Amazonas, Brasil \\ E-mail: profamariaisabel@ufam.edu.br \\ Eulina Maria Leite Nogueira \\ ORCID: https://orcid.org/0000-0002-7725-6464 \\ Universidade Federal do Amazonas, Brasil \\ E-mail: eleite@ufam.edu.br
}

\begin{abstract}
Resumo
Esse artigo apresenta um olhar para as educadoras do campo a partir da ação Escola da Terra, do PRONACAMPO. Foi desenvolvida no âmbito da disciplina Políticas Públicas e Educação do Campo, ofertada no segundo semestre de 2021, no Programa de Pós-Graduação em Ensino de Ciências e Humanidades (PPGECH) da Universidade Federal do Amazonas - UFAM, Unidade de Humaitá - IEAA. O objetivo geral é analisar se as ações da Escola da Terra têm refletido na atuação docente das educadoras amazonenses, considerando o questionamento que impulsiona a pesquisa: De que modo as ações da Escola da Terra têm refletido na prática pedagógica das educadoras do campo no contexto amazonense? Buscou-se, então, refletir sobre a prática pedagógica das educadoras amazonenses; discutir sobre o curso de formação pedagógica ofertado pela Escola da Terra; e entender se a condição feminina interfere na atuação docente das educadoras do campo. O amparo teórico-metodológico tem como base a metodologia pós-crítica em Educação, a partir de autores que transitam entre os campos de prefixos "Pós" trazidos por Meyer e Paraíso (2012), ancorados nos estudos feministas e de gênero, Berth (2020) e Holanda (2020). A produção de dados se deu a partir da entrevista narrativa, Andrade (2012) e análise documental, Ludke e André (2013). A análise dos resultados foi feita a partir de uma abordagem qualitativa, segundo Gastaldo (2018) e sugere que as ações da Escola da Terra não alcançaram as educadoras entrevistadas e não refletem nas práticas pedagógicas desenvolvidas. A condição feminina apareceu como influência significativa na ideia de empoderamento dos sujeitos no processo de resistência e busca por uma educação autônoma e emancipatória.
\end{abstract}

Palavras-chave: Educação do campo; Práticas pedagógicas; Formação docente; Escola da Terra; Gênero.

\begin{abstract}
This article presents a look at the field educators from the action Escola da Terra, from PRONACAMPO. It was developed in the context of the subject Public Policies and Education of the Field, offered in the second semester of 2021, in the Graduate Program in Teaching of Sciences and Humanities (PPGECH) at the Federal University of Amazonas - UFAM, Humaitá Unit - IEAA. The general objective is to analyze whether the actions of the Escola da Terra have been reflected in the teaching activities of women educators in Amazonas, considering the question that drives the research: How have the actions of the Escola da Terra reflected on the teaching practice of women educators in the field in the Amazon context? We sought, then, to reflect on the pedagogical practice of women educators in Amazonas; to discuss the pedagogical training course offered by the Escola da Terra; and to understand if the feminine condition interferes in the teaching performance of women educators in the field. The theoretical and methodological support is based on the post-critical methodology in Education, based on authors who move between the prefix "Post" fields brought by Meyer and Paradise (2012), anchored in feminist and gender studies, Berth (2020) and Holland (2020). Data production was from the narrative interview, Andrade (2012) and document analysis, Ludke and André (2013). The
\end{abstract}


analysis of the results was made from a qualitative approach, according to Gastaldo (2018) and suggests that the actions of the Escola da Terra did not reach the interviewed educators and are not reflected in the pedagogical practices developed. The feminine condition appeared as a significant influence on the idea of empowerment of the subjects in the process of resistance and search for an autonomous and emancipatory education.

Keywords: Rural education; Pedagogical practices; Teacher training; Escola da Terra; Gender.

\section{Resumen}

Este artículo presenta una mirada a los educadores de campo de la acción Escola da Terra, de PRONACAMPO. Fue desarrollado en el ámbito de la asignatura Políticas Públicas y Educación del Campo, ofrecida en el segundo semestre de 2021, en el Programa de Posgrado en Enseñanza de Ciencias y Humanidades (PPGECH) de la Universidad Federal de Amazonas - UFAM, Unidad de Humaitá - IEAA. El objetivo general es analizar si las acciones de la Escola da Terra se han reflejado en las actividades pedagógicas de las educadoras de la Amazonia, considerando la pregunta que impulsa la investigación: ¿Cómo se han reflejado las acciones de la Escola da Terra en la práctica pedagógica de las educadoras de campo en el contexto amazónico? Buscamos, entonces, reflexionar sobre la práctica docente de las educadoras de Amazonas; discutir el curso de formación pedagógica ofrecido por la Escola da Terra; y comprender si la condición femenina interfiere en el desempeño docente de las educadoras en el campo. El soporte teórico y metodológico se basa en la metodología postcrítica en Educación, a partir de autores que se mueven entre los campos de los prefijos "Post" aportados por Meyer y Paradise (2012), anclados en los estudios feministas y de género, Berth (2020) y Holland (2020). La producción de datos se basó en la entrevista narrativa, Andrade (2012) y el análisis documental, Ludke y André (2013). El análisis de los resultados se hizo desde un enfoque cualitativo, según Gastaldo (2018) y sugiere que las acciones de la Escola da Terra no llegaron a los educadores entrevistados y no se reflejan en las prácticas pedagógicas desarrolladas. La condición femenina apareció como una influencia significativa en la idea de empoderamiento de los sujetos en el proceso de resistencia y búsqueda de una educación autónoma y emancipadora.

Palabras clave: Educación rural; Prácticas pedagógicas; Formación de profesores; Escola da Terra; Género.

\section{Considerações Iniciais}

Olhar para as mulheres educadoras que atuam no campo é um exercício que deve ser encarado sob o prisma apontado por Zanella (2012, p. 169), ao afirmar que é importante "olhar o que se fez e o que se deixou de fazer, as linhas e as entrelinhas, o visto e o não visto". A atuação docente feminina na educação do campo precisa ser enxergada de modo a questionar seus impasses e desafios, os quais perpassam o âmbito acadêmico, posto que, segundo Cunha (2016, p. 02) o ponto de atenção não é criar um embate entre homens e mulheres trabalhadores da educação, antes disso, intenta-se "trazer à tona comprometimentos ideológicos no que diz respeito a luta por direitos", por respeito e valorização da mulher que atua como docente na educação do campo.

É fundamental que se entenda quais os dilemas enfrentados por essas mulheres que atuam no campo e como elas lidam com seus desafios. Cunha (2016, p.03) destaca que a mulher acumula desafios inerentes a sua prática profissional e à "dificuldade de romper com estruturas patriarcais, o maior desafio está em alcançar um lugar de protagonismo, obter reconhecimento e reconhecer-se enquanto trabalhadora". A fim de sanar um dos desafios que limitam a prática docente, a falta de formação, uma das ações do Pronacampo visa capacitar educadores em todo o Brasil, através do programa Escola da Terra, que segundo Collares, Xavier e Albuquerque (2019, p. 01) “compreende ações que envolvem formação continuada através de Curso de Aperfeiçoamento, de 180 horas, na Modalidade Alternância, composta de dois períodos denominados de Tempo-Universidade e Tempo Comunidade”.

O objetivo geral dessa pesquisa é analisar se as ações da Escola da Terra têm refletido na atuação docente das educadoras amazonenses, considerando o questionamento que impulsiona a pesquisa: De que modo as ações da Escola da Terra têm refletido na prática pedagógica das educadoras do campo no contexto amazonense? A partir daí buscou-se, então, refletir sobre a prática pedagógica das educadoras amazonenses, discutir sobre o curso de formação pedagógica ofertado pela Escola da Terra e enfim, entender se a condição feminina interfere na atuação docente das educadoras do campo. 
Essas ações são necessárias para que se possa "promover a melhoria das condições de acesso, permanência e aprendizagem dos estudantes [...], por meio do apoio à formação de professores" (Collares; Xavier; Albuquerque, p.02), pois dessa forma a escola se tornará um espaço de aprendizagem, vivência social e cultural.

\section{Caminhos Metodológicos}

O amparo metodológico da pesquisa está inspirado nos estudos pós-críticos em educação, a partir do que propõem Meyer e Paraíso (2012). Esse campo teórico-metodológico dialoga com as teorias de prefixo "pós", como pósestruturalismo, pós-modernismo, pós-colonialismo, estudos culturais e estudos de gênero. A escolha metodológica justifica-se pela necessidade de um olhar mais amplo sobre as questões de gênero, como as relações de poder que envolve o universo feminino, o qual ainda sofre com marcas da opressão do patriarcado que se estende por anos e que tem sido alvo de reflexões e resistências de movimentos sociais contemporâneos.

Gastaldo (2018, p. 09) acredita que a utilização de um referencial teórico pouco conhecido em favor de uma equidade educacional e social pode parecer uma má escolha. Entretanto defende que é exatamente isso que fazem os autores pós-críticos, visto que se propõem a "examinar o status quo para desnaturalizá-lo, o que significa envolver-se em uma ambiciosa tarefa de propor modos alternativos de pensar, falar [...] e remodelar as metodologias de pesquisa". Dessa forma, pretende-se evitar que se torne uma simples ferramenta de reprodução social.

A abordagem utilizada na pesquisa é qualitativa, visto que, como afirma Gastaldo (2018), a utilização dessa abordagem exige uma combinação de coragem, clareza metodológica e otimismo, principalmente ao se tomar políticas públicas e gênero como objeto de pesquisa. A autora defende que essa abordagem tem crescido em aceitação no âmbito da pesquisa brasileira.

A análise dos dados produzidos durante o processo investigativo segue os princípios da entrevista ressignificada, proposta por Andrade (2012). Nesse processo de ressignificação, a autora defende que é possível, a partir das narrativas, reconstruir as significações atribuídas pelos sujeitos em seus discursos, posto que, enquanto falam de si, de suas experiências e vivências, reinventam o passado, atribuindo um novo sentido ao presente.

Ao entrevistar professoras que atuam na educação do campo, espera-se refletir sobre a prática pedagógica por elas desenvolvidas e entender se há alguma influência de sua condição feminina nesse processo. Isso é viável porque Andrade (2012) explica que a partir da reconstrução dos fatos narrados é possível estabelecer comunicação ou relação com determinados fatos, instantes e/ou momentos decisivos para a constituição de experiências vividas.

Os sujeitos da pesquisa são professoras que atuam na educação do campo, no Estado do Amazonas, em diferentes municípios e campesinatos, conceito entendido aqui, a partir de Costa e Carvalho (2012), autores que definem o termo como um conjunto de famílias camponesas existentes em um território.

Os municípios foram representados a partir das localidades dos (as) mestrandos (as) que cursavam a disciplina Educação do Campo, no segundo semestre de 2021, do PPGECH/UFAM, sendo 05 (cinco) professoras do campo, dos municípios de Presidente Figueiredo, Barreirinha, Humaitá, Apuí e Parintins, todos pertencentes ao Estado do Amazonas.

Foi realizada ainda, uma análise documental, a partir do Manual da Escola da Terra, com base na proposta de Ludcke e André (2013). As autoras definem que essa estratégia de produção de dados se constitui em uma técnica valiosa de abordagem de dados qualitativos. De igual modo, destacam que a utilização de documentos é vantajosa por possuir um baixo custo ao pesquisador, requerendo apenas tempo e atenção para seleção e análise dos dados obtidos. 
A escolha do Manual da escola da Terra se deu pelo fato de a pesquisa se propor a analisar se as ações desse programa têm refletido na atuação docente das professoras, ou seja, a escolha não se deu de forma aleatória, como alertam Ludcke e André (2013), mas com um propósito preestabelecido.

O caminho metodológico sugerido intenta proporcionar um olhar mais íntimo voltado as educadoras do campo, entendendo que a inspiração nos estudos pós-críticos pode contribuir, como enfatiza Gastaldo (2018, p. 12), "para demonstrar que a centralidade do/a pesquisador/a como principal ferramenta de pesquisa qualitativa resgata a subjetividade humana [...] a fim de produzir saberes mais refinados e agudos", o que explica a relevância da pesquisa qualitativa pós-crítica, vista como uma metodologia flexível, inserida em contextos específicos.

\section{Aproximações Teóricas}

O exercício da prática de olhar para a mulher em seus diversos contextos socioculturais tem sido amplamente discutido pelo movimento feminista. A educação do campo é um desses cenários em que a mulher deve ser vislumbrada sob uma perspectiva que possibilite reconhecer a influência de sua condição feminina em seu campo de atuação.

Berth (2020) destaca que no movimento feminista tem reestruturado as bases para o entendimento e aplicabilidade capazes de detectar as implicações que envolvem as relações de poder, no tocante as questões de gênero, tendo como ponto de partida os lugares sociais das mulheres.

Holanda (2020) chama a atenção à consciência de opressão dos processos colonizadores, campo com o qual o feminismo dialoga e que ampara as questões da educação do campo, visto ser uma temática envolta de desprestígio e que requer um processo intenso de resistência, a fim de diminuir o impacto da cultura eurocentrada na educação.

Os estudos decoloniais denunciam, segundo Holanda (2020), a imbricação estrutural da heteronormatividade, classificação racial e sistema capitalista. Nesse contexto, é preciso entender que é urgente a recuperação da organização social das comunidades e movimentos sociais, o que atrai um papel de grande responsabilidade às mulheres que atuam na educação do campo. Graça (2020) enfatiza que

O debate feminista terá um lugar central na construção do movimento agroecológico a partir do momento que as mulheres, principalmente as mulheres do campo, indígenas, negras e de populações tradicionais, começam a trazer suas pautas, demandas e necessidades de reconhecimento dentro do movimento, partindo da ideia de que "sem feminismo não há agroecologia", construindo assim uma nova agenda para o movimento ambiental no Brasil e em toda a América Latina. (Graça, 2020, p. 286).

Essa perspectiva evidencia a necessidade de que as mulheres educadoras se posicionem como protagonistas diante das diferentes questões associadas a relação gênero/educação. Lusa (2012, p. 96) destaca que "a questão do poder patriarcal exercido pelo homem sobre a mulher sempre esteve presente nas discussões feministas, porém, atualmente esta discussão questiona como se constroem historicamente as relações de poder, perpetuando as desigualdades de gênero". A autora denuncia que as desigualdades percebidas nessas relações, bem como a violência e a exploração praticadas contra a mulher estão ligadas a manutenção do capitalismo. Lusa (2012) acredita que singelas mudanças podem ser observadas em diferentes contextos, inclusive na educação do campo.

Muito embora reconheça-se a ocorrência de tais modificações, adverte-se que as mesmas não ocasionam transformações estruturais nos tradicionais e desiguais papéis de gênero no espaço rural do semiárido. A razão, possivelmente repousaria na forte impregnação da cultura patriarcal e machista que é comum à cultura ocidental, a qual se faz mais ou menos forte - todavia sempre presente - a depender dos diferentes contextos sociais. Neste contexto, está se tratando da emergência de um "novo mundo rural", que adentra no imaginário de homens e mulheres do campo - do sertanejo, do agrestino, do camponês, pequeno proprietário, pequeno arrendatário, proletário rural, ocupante ou assentado da reforma agrária (Lusa, 2012, p. 97). 
Outro ponto de atenção volta-se ao que se conhece como divisão sexuada do trabalho. Nesse sentido, questiona-se a possibilidade de a condição feminina influenciar ou não as atribuições das educadoras do campo em contraste com as atividades dos homens. Kergoat (2012) defende que as condições vivenciadas por homens e mulheres não são produtos de um destino biológico, mas representam construções sociais, ou seja, tanto homens quanto mulheres são seres biológicos, mas, acima de tudo, seres socias, que desenvolvem relações nas quais dividem socialmente o trabalho, com base em suas construções históricas.

Dessa forma, Carvajal (2020) pontua a urgência do reconhecimento de uma outra existência, a qual demanda a redistribuição dos benefícios do trabalho e o compartilhamento de reivindicações e resistências, pois nada justifica que as mulheres sejam vistas como menos capazes ou menos produtivas, simplesmente por sua condição feminina. A autora enfatiza que "só nos resta então, como mulheres, traduzir isso em políticas públicas que começam nas comunidades e devem chegar até o governo nacional" (Carvajal, 2020, p. 203).

Diante dessas pontuações teóricas, volta-se a análise de conceitos relevantes sobre a educação do campo e sobre as políticas públicas que versam sobre esse tema, a fim de entender o impacto delas sobre a prática das mulheres educadoras que atuam no campesinato.

\subsection{A educação do campo}

O conceito de Educação no campo é relativamente novo é está associado ao processo de lutas pelo atendimento às demandas dos camponeses, principalmente dos integrantes de movimentos sociais, como o Movimento Sem Terra (MST). Caldart (2003) afirma que "quase ao mesmo tempo em que começaram a lutar pela terra, os sem-terra do MST também começaram a lutar por escolas e, sobretudo, para cultivar em si mesmos o valor do estudo e do próprio direito de lutar pelo seu acesso a ele" (p.62). A autora afirma que o movimento acabou fazendo uma verdadeira ocupação da escola:

As famílias sem-terra mobilizaram-se (e mobilizam-se) pelo direito à escola e pela possibilidade de uma escola que fizesse diferença ou tivesse realmente sentido em sua vida presente e futura (preocupação com os filhos). As primeiras a se mobilizar, lá no início da década de 80 , foram as mães e professoras, depois os pais e algumas lideranças do Movimento; [...] decidiu, pressionado pela mobilização das famílias e das professoras, tomar para si ou assumir a tarefa de organizar e articular por dentro de sua organicidade esta mobilização, produzir uma proposta pedagógica específica para as escolas conquistadas, e formar educadoras e educadores capazes de trabalhar nesta perspectiva (Caldart, 2003, p. 62).

Vale destacar que esse processo de ocupação da escola, como nomeia Caldart (2003), o MST passou a conduzir reflexões importantes em relação ao que se pensa sobre a escola, sua concepção e quais práticas e metodologias deveriam ser adotadas em uma escola inserida em um movimento social. Nesse contexto, o diálogo com a educação popular e outras experiências de escolas alternativas se tornou de extrema relevância.

Nesse processo de reflexões e diálogos, Caldart (2003) aponta algumas lições que contribuem com a perspectiva da educação do campo. Na primeira delas, afirma que a escola não move o campo, mas o campo não se move sem a escola e segue afirmando que quem faz a escola do campo são os povos do campo, organizados e em movimento.

Outra lição sugere que as lutas sociais dos povos do campo estão produzindo a cultura do direito à escola no campo, o que reitera a ideia de que sem estudo não se vai a lugar algum. Ela defende que quanto mais amplos são os objetivos de uma organização maior é a valorização da escola pelos seus sujeitos e que a escola ajuda a formar lutadores do povo quando trabalha com dois elementos básicos: raiz e projeto, sendo assim: 
Toda vez que uma escola desconhece e ou desrespeita a história de seus alunos, toda vez que se desvincula da realidade dos que deveriam ser seus sujeitos, não os reconhecendo como tal, ela escolhe ajudar a desenraizar e a fixar seus educandos num presente sem laços. E se isto acontecer com um grupo social desenraizado ou com raízes muito frágeis, isto quer dizer que estas pessoas estarão perdendo mais uma de suas chances (e quem garante que não a última?) de serem despertadas para a própria necessidade de voltar a ter raiz, a ter projeto. Do ponto de vista do ser humano isto é muito grave, é violentamente desumanizador (Caldart, 2003, p. 70).

$\mathrm{Na}$ mesma pesquisa a autora esclarece que a escola do campo "precisa ser ocupada pela pedagogia do movimento que forma os sujeitos sociais do campo [...] e que as relações sociais são a base do ambiente educativo de uma escola. São elas que põem em movimento as pedagogias” (Caldart, 2003, p.73). Para que essas lições sejam colocadas em prática, faz-se necessário um coletivo de educadores engajados, a fim de se garantir um ambiente educativo adequado para uma escola em movimento, como a escola do campo.

Bitencourt e Boemer (2019) ressaltam que os debates atuais em torno da educação do campo emergem para além das discussões, proposições e estratégias políticas e que os movimentos sociais do campo se mantém com uma postura reivindicatória de resistência diante da necessidade do estado cumprir seu papel frente à reforma agrária e no atendimento de outros direitos como o acesso e permanência dos cidadãos do campo no âmbito educacional, desde a educação infantil até a pós-graduação, em todos os seus níveis. Nesse sentido, Caldart (2002) entende a educação do campo como:

Um projeto de educação que reafirma como grande finalidade de ação educativa ajudar no desenvolvimento mais pleno do ser humano, na sua humanização e inserção crítica na dinâmica da sociedade de que faz parte; que compreende que os sujeitos se humanizam ou se desumanizam sob condições materiais e relações sociais determinadas; que nos mesmos processos em que produzimos nossa existência nos produzimos como seres humanos; que as práticas sociais, e entre elas especialmente as relações de trabalho, conformam (formam ou deformam) os sujeitos. É por isso que afirmamos que não há como verdadeiramente educar sujeitos do campo sem transformar as circunstâncias sociais desumanizantes, e sem prepará-los para ser os sujeitos destas transformações (...). A educação do campo é intencionalidade de educar e reeducar o povo que vive no campo na sabedoria de se ver como "guardião da terra", e não apenas seu proprietário ou quem trabalha nela. Ver a terra como sendo de todos que podem se beneficiar dela. Aprender a cuidar da terra e aprender deste cuidado algumas lições de como cuidar do ser humano e de sua educação (Caldart, 2002, p.32-33).

A partir dessa concepção de educação do campo é que passaremos a analisar a Escola da Terra como uma política pública que faz parte do Programa Nacional de Educação do Campo, Pronacampo, a fim de entender se esse processo de formação pedagógica tem influenciado na prática pedagógica das educadoras do campo (Costa, 2019).

É mister que a educação esteja atenta às especificidades relacionadas aos sujeitos inseridos no contexto de ensino, valorizando-os como atores principais nesse processo. Desse modo, Costa (2019) entende que seja possível desmistificar a ideia de que os sujeitos do campo são atrasados ou pobres culturalmente.

\subsection{O Pronacampo e a Escola da Terra}

A discussão em torno de políticas públicas voltadas a Educação do campo é uma tarefa que envolve uma relação de conquistas muito lentas ao longo da história, mas implica também em construções relevantes e significativas. Apesar disso, Bitencourt e Boemer (2019, p. 136) destacam que "faltam ainda ações políticas que propiciem, de fato, a efetivação desses avanços conquistados, considerando que muitas ações ainda estão limitadas enquanto programas e, portanto, não estão asseguradas pela lei”.

O Pronacampo foi criado pelo Decreto $\mathrm{n}^{\mathrm{o}} 7.352$ e instituído por meio da Portaria $\mathrm{n}^{\mathrm{o}} 86$, de $1^{\circ}$ de fevereiro de 2013. Sua finalidade é oferecer apoio financeiro e técnico a fim de viabilizar as políticas públicas no campo. O Programa visa à qualificação da educação do campo mediante melhoria do ensino, formação de professores, produção 
de material didático próprio, melhoria de infraestrutura, entre outros (Silva, 2018).Está estruturado sob quatro eixos: Gestão e Práticas Pedagógicas; Formação de Professores; Educação de Jovens e Adultos, Educação Profissional e Tecnológica; e Eixo Infraestrutura Física e Tecnológica. No eixo II, formação inicial e continuada de professores, encontra-se a ação Escola da Terra.

De acordo com o Manual da Escola da Terra, essa ação busca promover o acesso, a permanência e a melhoria das condições de aprendizagem dos estudantes do campo e quilombolas em suas comunidades, tendo como objetivos

Promover a formação continuada específica de professores para que atendam às necessidades de funcionamento das escolas do campo e das localizadas em comunidades quilombolas; oferecer recursos didáticos e pedagógicos que atendam às especificidades formativas das populações do campo e quilombolas (Brasília, 2006).

A proposta da Escola da Terra visa fortalecer o desenvolvimento de propostas pedagógicas e metodologias, de modo a se adequarem às comunidades que serão atendidas, de maneira que possam elevar o desempenho escolar dos estudantes. Viera e Maciel (2017) acrescentam que

O Programa Escola da Terra constitui-se através da formação continuada dos docentes sobre a concepção dos diferentes territórios emersos em saberes e práticas cotidianas dos sujeitos. Os formadores problematizam estas realidades que servem de base para a construção do currículo crítico e emancipatório dos educadores e educandos, a partir de suas identidades agropesqueira, da agricultura e outras práticas socioculturais. (Vieira; Maciel, 2017, p. 36).

O Manual sugere que a implementação da formação continuada aconteça com a oferta de curso de aperfeiçoamento, com carga horária total mínima de 180 horas, organizadas em períodos formativos, denominados tempo-universidade e tempo escola-comunidade.

Esta lógica de pensar uma formação no tempo escola e tempo comunidade, faz parte de uma concepção de educação atrelada a Pedagogia da Alternância, que possibilita aos professores do campo estudar e ter acesso ao conhecimento, não apenas como algo dado por outrem, mas como um conhecimento conquistado, construído a partir da problematização de sua realidade (Vieira; Maciel, 2017, p.40).

Em 2013, sete universidades federais foram selecionadas para participar do projeto-piloto da Escola da Terra, em quatro das cinco regiões do país. O projeto distribuiu 7,5 mil vagas. A Universidade Federal do Amazonas (Ufam) ofertou 1,5 mil. As da Bahia (UFBA), do Pará (UFPA), de Pernambuco (UFPE), do Rio Grande do Sul (UFRGS), de Minas Gerais (UFMG) e do Maranhão (UFMA), mil vagas cada uma.

Vieira e Maciel (2019) entendem que a formação continuada torna-se necessária por proporcionar ao professor um diálogo entre a discussão teórica e a metodológica, proporcionada pelo Programa Escola da Terra, momento em que é possível relacionar sua prática docente no campo, às vivências do curso. Para que isso aconteça, a formação deve reconhecer a realidade em que esse sujeito-professor se encontra.

Dito isso, entende-se que a formação continuada oferecida pela Escola da Terra tende a promover a valorização dos sujeitos do campo, partindo do (a) professor (a), o qual, depois de formado, estenderá a aprendizagem adquirida e aperfeiçoada aos estudantes camponeses com os quais trabalha.

\section{Análise dos Resultados}

Ao todo foram ouvidas 05 (cinco professoras) que atuam em escolas do campo do interior do Estado do Amazonas. As entrevistas aconteceram de forma virtual, devido a distância e dificuldade de acesso aos municípios em 
que as entrevistadas atuam. Foram realizadas cinco indagações para nortear a entrevista. Na primeira delas, as professoras deveriam descrever como enxergavam a educação do campo. Para fins de preservar o anonimato das entrevistadas, elas serão identificadas como P01, P02, P03, P04 e P05.

A P01 apontou a educação do campo como uma modalidade necessária para compensar o esquecimento da população, que se estende há décadas. P02 a definiu como precária, justificando sua visão por conta da falta de investimento, o que leva os professores a uma situação de desânimo com e no ambiente de trabalho. Já a P03 comentou que a educação do campo já foi bem esquecida, mas que hoje passou a ser muito visada, com organização e planejamentos destinados e adaptados a sua realidade, o que refletiu na melhoria dos resultados.

A P04 e P05 apresentaram posicionamento contrário, pois entendem que a educação do campo ainda não é encarada com a devida importância, ainda precisa de maior destaque na agenda de políticas públicas. Destacaram ainda a necessidade de revisar o currículo, de forma que atenda a necessidade dos sujeitos do campo e de maior investimento na qualificação dos profissionais, visto que a realidade do campo é muito diferente daquilo que é visto na universidade.

Hilleshein (2018, p.14) concorda que a educação do campo foi historicamente negada, por muitas vezes considerada arcaica, atrasada, mas alerta que isso se deve ao fato de que seus formadores raramente tiveram origem no campo. Dessa forma, "não conhecendo o campo, sua cultura, sua tecnologia, seu manejo, como poderiam auxiliar na educação dos que lá trabalham?”. O autor defende, ainda, que não há como pensar na formação integral dos sujeitos do campo sem que sejam respeitados os espaços do campo e sem que haja uma vinculação da educação à sua realidade; a única saída, segundo Hilleshein (2018) é respeitar a diversidade do campo e formar professores-educadores com um discurso voltado àquele espaço.

Partindo para a segunda indagação, as professoras foram convidadas a comentar sobre sua experiência na educação do campo. A P01 comentou que sua escolha se deu por conta de ter crescido em uma comunidade do campo e suas memórias a direcionaram a pesquisar o campesinato. A P02 foi bem direta, apenas citou que sua experiência no campo foi/é muito ruim. Já a P03, citou que já são muitos anos subindo e descendo barrancos e estradas de terra, mas alegou estar feliz por hoje vislumbrar melhorias e investimentos na educação do campo.

A P04 reconheceu que ainda está aprendendo a atuar na educação do campo, pois ela é recém-formada e o campo exige estratégias diferenciadas de ensino. Ela cita que precisou adaptar sua linguagem formal da cidade e ajustar ao que ela chama de língua cultural do povo. A P05 compartilhou que atua a 09 (nove) anos em escolas rurais e cita que vivenciou inúmeros desafios, tanto na parte pedagógica, escolarização, material didático, quanto na parte estrutural e de instalações físicas. Destacou que sua prática era baseada em suas vivências e raramente era orientada sobre metodologias ou teve acesso a documentos normativos.

Sobre a identidade docente, Isobe e Rezende et al (2019) defendem que ela deve ser compreendida como um processo em construção constante e que se consolida de acordo com os significados sociais da sua profissão, que ora transita entre tradições e contradições. Segundo as autoras, o professor (a) deve compreender a formação prévia do exercício profissional e precisa "estar seguro de sua prática por meio da compreensão do significado dos valores que ela representa" (Isobe; Rezende, 2019, p. 224).

Sendo assim, é preocupante quando se ouve um relato de uma educadora afirmando que está aprendendo a atuar no campo, ou que desenvolve suas práticas sem orientação metodológica específica, pois a educação do campo requer uma atenção especial, como destaca Caldart (2003)

Nossa sensibilidade de educadores já nos permitiu perceber que existe algo diferente e que pode ser uma alternativa em nosso horizonte de trabalhador da educação, de ser humano. Precisamos aprender a 
potencializar os elementos presentes nas diversas experiências, e transformá-los em um movimento consciente de construção das escolas do campo como escolas que ajudem neste processo mais amplo de humanização, e de reafirmação dos povos do campo como sujeitos de seu próprio destino, de sua própria história (Caldart, 2003, p. 61).

Ao serem questionadas se possuíam algum conhecimento sobre a ação do Pronacampo, Escola da Terra, três professoras relatam conhecer. P01 citou que era um programa que sobreviveu aos desmontes dos últimos anos, a partir da ascensão da extrema direita. P02 e P03 disseram se tratar de um projeto, cujo resultado poderia ser visualizado em longo prazo, mas P03 destacou não haver participado ainda, por falta de oportunidade. Já P04 e P05 informaram desconhecer tal ação.

Sobre a participação de outras formações direcionadas a educação do campo, apenas P01 e P04 relataram ter participado, oferecido pela Universidade Federal do Espírito Santo e pela Seduc/AM, respectivamente. As demais professoras informaram que nunca participaram de formação específica, mas destacaram que recebiam informações gerais, no início do ano letivo.

Nesse sentido, vale refletir sobre o motivo pelo qual as formações oferecidas pela Escola da Terra não têm alcançado essas professoras. Segundo dados da Faculdade de Educação (FACED) da Universidade Federal do Amazonas (UFAM), a Escola da Terra já está na quarta edição do seu curso de formação, atendendo professores de todo o Estado do Amazonas.

No mês de agosto de 2021, a faculdade ofertou mais uma edição do Curso de Aperfeiçoamento em Educação do Campo Práticas Pedagógicas, ministrado em Humaitá, Iranduba, Itacoatiara, Manicoré, Presidente Figueiredo e São Sebastião do Uatumã, alcançando cerca de 2.800 professores, segundo Heloísa Borges, coordenadora do curso da Faced.

A primeira versão do curso ocorreu em 2014, atendendo 1.542 professores das escolas municipais do campo em 18 municípios. Em sua segunda edição, a atividade teve início em maio de 2016, e capacitou 1.038 profissionais de 24 municípios. A terceira versão da formação deu-se em 2018, e chegou a 300 professores de cinco municípios. Somados às turmas de 2021, a Faced terá respondido pelo aperfeiçoamento profissional de três mil professores da educação básica de 53 municípios do Amazonas (Borges, 2021).

A coordenadora explica que a formação é dividida em dois eixos, no primeiro, o curso busca discutir o trabalho no campo, a comunidade e as identidades e no segundo momento, a atividade docente e é nessa etapa que discute-se o “projeto político-pedagógico, currículo, experiências com pesquisa, como ensinar as crianças de séries multisseriadas [...] desenvolvendo o conhecimento através dos saberes deles com os saberes escolares" (Borges, 2021).

Ao prosseguir com a entrevista, as professoras foram questionadas se elas entendiam que sua condição feminina contribuía ou influenciava de alguma forma na sua atuação como educadora do campo. Seguem os relatos:

P01: "Não apenas minha condição feminina, mas também minha condição de filha de camponeses são elementos que contribuem para resgatar a identidade do povo do campo".

P02: "Existe uma divergência grande no Brasil de onde é o lugar da mulher, no meio rural é muito mais aparente, por se tratar de pessoas com baixa escolaridade, acesso as informações e cultura local. Vejo o meu papel como um ponto de partida, mostrar a mudança e melhorar a vida das mulheres no meio rural, quebrar paradigmas, sei que isso é um processo longo, e que o fardo é pesado para uma pessoa, mas me vejo como um dente na engrenagem que faz girar a evolução na educação do campo".

P03: "Nossa condição feminina nos permite ser muito mais pacientes, com visão ampliada para a educação dos alunos".

P04: "Pelo fato de estar disposta a lutar por uma educação de qualidade independente do local que você atua”. 
P05: “As mulheres ganharam espaço na sociedade, sua força, empoderamento, olhar crítico e reflexivo, o que pode alicerçar sua prática docente. Uma mulher encoraja outras mulheres através de suas experiências e vivências cotidianas".

De acordo com P01, a sua atuação no resgate da identidade dos sujeitos do campo está relacionada à forma como suas memórias de filha de camponeses e a sua condição feminina interagem. Silva (2014) explica que a produção da identidade oscila entre dois movimentos, de um lado os processos que fixam ou estabilizam a identidade e do outro, os que a subvertem e desestabilizam.

Desse modo, essa construção de identidade relaciona-se não apenas com “as questões ‘quem nós somos’ ou 'de onde nós viemos', mas muito mais com as questões 'quem nós podemos nos tornar"” (Silva, 2014, p. 109). Logo, fica evidente que a professora deve ter consciência de sua condição e do seu papel de mediar esse processo de autoconhecimento e emancipação.

A P02 reconhece seu papel como ponto de partida para a mudança e quebra de paradigmas que a educação requer. A educadora destaca a mulher como sujeito importante no meio rural, assim como Cunha (2016), ao pontuar a reprodução de relações de dominação, a qual se manifesta de forma expressiva quando se trata das relações homem/mulher, especialmente em se tratando do acesso aos direitos e consolidação da cidadania.

P03 destaca a característica da paciência como um atributo feminino, como condição para que sua atuação docente seja mais eficiente. Esse pensamento parece estigmatizado, pois durante anos a docência foi vista como uma profissão mais propícia à mulher, por associar-se aos cuidados maternos, atribuições exclusivamente femininas.

A luta por escolas do campo passa por outras lutas que ocorrem tanto no nível da estrutura quanto da superestrutura, tais como desfazer estigmas socialmente construídos que colocam a população camponesa em situação de inferioridade, o espaço do campo como lugar de atraso. No que diz respeito ao papel da mulher, ainda mais destituída de cidadania, na dificuldade de romper com estruturas patriarcais, o maior desafio está em alcançar um lugar de protagonismo, obter reconhecimento e reconhecer-se enquanto trabalhadora (Cunha, 2016, p. 03).

P04 entende que sua postura na luta por uma educação de qualidade independe do lugar onde atua e não atribuiu influência de sua condição feminina nesse processo. Já a P05 destaca a força e o empoderamento feminino como fatores relevantes na sua prática pedagógica. Berth (2020, p. 54) aponta que o empoderamento vem a ser um fator resultante da "junção de indivíduos que se reconstroem e se desconstroem em um processo contínuo que culmina em empoderamento prático da coletividade, tendo como resposta as transformações sociais desfrutadas por todos e todas". A autora afirma que esse empoderamento é um processo gradual, ou seja, o fato de um sujeito que pertence a um grupo oprimido desenvolver um pensamento crítico não o retirará da condição estrutural de degradação. É necessário que a sua comunidade se empodere, a fim de saírem coletivamente da condição opressora. (p.55).

É importante refletir sobre as experiências e vivências citadas pela educadora, pois elas podem contribuir significativamente nesse processo de empoderamento, posto que o "silenciamento dos grupos oprimidos e o endurecimento do conveniente desinteresse dos grupos dominantes em discutir as matrizes opressoras deixaram um atraso na produção do conhecimento" (p.57). Caldart (2003) defende a necessidade de construção de uma escola do campo que valorize seus sujeitos.

Uma escola do campo não é, afinal, um tipo diferente de escola, mas sim é a escola reconhecendo e ajudando a fortalecer os povos do campo como sujeitos sociais, que também podem ajudar no processo de humanização do conjunto da sociedade, com suas lutas, sua história, seu trabalho, seus saberes, sua cultura, seu jeito. Também pelos desafios da sua relação com o conjunto da sociedade. Se é assim, ajudar a construir escolas do campo é, fundamentalmente, ajudar a constituir os povos do campo como sujeitos, organizados e em movimento. Porque 
não há escolas do campo sem a formação dos sujeitos sociais do campo, que assumem e lutam por esta identidade e por um projeto de futuro. Somente as escolas construídas política e pedagogicamente pelos sujeitos do campo, conseguem ter o jeito do campo, e incorporar neste jeito as formas de organização e de trabalho dos povos do campo (Caldart, 2003, p. 66).

Desse modo, não é preciso estar no dia a dia das educadoras para perceber que existem inúmeros desafios a serem superados, como destacam Felberg e Silva (2017). É possível notar a marginalidade e exclusão em que o campesinato se encontra, nítido através da ineficácia de políticas públicas ou a falta do alcance apropriado.

Entende-se, portanto, que as educadoras exercem um papel de relevância extremada no desenvolvimento de um olhar crítico e emancipatório e, para tal, requer um olhar mais eficiente, no que tange a formulação, execução e avaliação de políticas públicas voltadas a educação do/no campo.

\section{Considerações Finais}

O caminho percorrido até essas considerações proporcionou uma reflexão sobre a atuação docente das educadoras amazonenses levando em conta o contexto da educação do campo no qual estão inseridas. Pouco se pode associar entre a formação da Escola da Terra e a prática narrada pelas professoras.

As educadoras apontam que o contato com formações específicas para a prática pedagógica no campo não faz parte da realidade de suas experiências profissionais, com exceção de duas professoras que chegaram a vivenciar uma atividade promovida pela Seduc/Am e de uma outra que procurou um curso de extensão na Universidade Federal do Espírito Santo.

Essa ausência de contato com as ações promovidas pela Escola da Terra, através da Faculdade de Educação da UFAM levanta um ponto de investigação para futuras pesquisas, pois é preciso entender o porquê de a ação não alcançar as pessoas que atuam diretamente na ponta do processo, junto aos sujeitos do campo.

Essa discussão sobre a eficiência dessa ação do Pronacampo como política pública precisa perpassar o campo da escrita científica e alcançar os formuladores e avaliadores das políticas educacionais, a fim de agir de modo efetivo e olhar de maneira mais sensível para os desafios vivenciados pelas mulheres que atuam na educação do campo.

Por fim, verificou-se que as educadoras entendem que a condição feminina pode proporcionar uma maior sensibilidade diante da proposta emancipadora e autônoma da educação do campo, ao mesmo tempo que as reflexões sobre as experiências e vivências repassadas aos estudantes e comunitários podem estimular a busca pelo empoderamento coletivo.

A partir dessa consciência de responsabilização individual e comunitária, será possível construir, mesmo que em longo prazo, uma visão de educação para cidadania, capaz de escrever novas histórias, independentemente da localização em que os indivíduos estiverem.

\section{Referências}

Andrade, S. S. (2012). A entrevista narrativa ressignificada nas pesquisas educacionais. In: Meyer, D. E; Paraíso, M. A. Metodologias de pesquisas pós-críticas em educação. Mazza edições.

Berth, J. (2020). Empoderamento.Sueli Carneiro: Jandaira.

Bitencourt, S; Boemer, L. A. (2019). Fundamentos da educação no campo. Uniasselvi.

Brasília (2006). Manual Escola da Terra. Ministério da Educação.

Caldart, R. S. A. (2003). Escola do Campo em movimento. Coletivo Nacional de Educação do MST e Instituto Técnico de Capacitação e Pesquisa da Reforma Agrária (ITERRA) Brasil. Currículo sem Fronteiras. 3(1), 60-81.

Caldart, R. S. (2002). Por uma Educação do Campo: traços de uma identidade em construção. In: Kolling, E.; Cerioli, P. R.; Caldart, R. S. (Orgs). Educação do campo: identidade e políticas públicas. Articulação Nacional "Por uma Educação do Campo" 
Research, Society and Development, v. 11, n. 2, e32211225873, 2022

(CC BY 4.0) | ISSN 2525-3409 | DOI: http://dx.doi.org/10.33448/rsd-v11i2.25873

Caldart, R, S. Org. (2012). Dicionário da Educação do Campo. Escola Politécnica de Saúde Joaquim Venâncio, Expressão Popular.

Camillo, C. M; Medeiros, L. M. (2018). In. David, C. Org. Reflexões e práticas na formação de educadores. EdUERJ.

Carvajal, J. P. (2020). Uma ruptura epistemológica com o feminismo ocidental. IN. Holanda, H. B. Pensamento feminista hoje: perspectivas decoloniais. Bazar do Tempo.

Collares, D; Xavier, N. R; Albuquerque, P. P. (2019). Escola da Terra: a formação docente como espaço reflexivo na interdependência entre extensão, Ensino e Pesquisa. IN. Gestão, avaliação e inovação no ensino superior. Ponta Grossa: Atena, 2019.

Costa, F. A.; Carvalho, H. M. (2012) Campesinato. IN. Caldart, R, S. Org. (2012). Dicionário da Educação do Campo. Escola Politécnica de Saúde Joaquim Venâncio, Expressão Popular.

Costa, M. G. (2020). Agroecologia, (eco)feminismos e "bem viver": emergências decoloniais no movimento ambientalista brasileiro. IN. Holanda, H. B. Pensamento feminista hoje: perspectivas decoloniais. Bazar do Tempo.

Cunha, H.S. (2016). A feminização da luta por escolas do campo: uma questão de gênero e classe. Entrelaçando. N.10, Ano V, Caderno Temático do II SIEC: Educação do Campo em Moviemento.

David, C. Org. (2018). Reflexões e práticas na formação de educadores. EdUERJ.

Felber, A; Silva, G. J. (2017). Contributos da educação do campo para formação de sujeitos autônomos: um estudo no assentamento Luis Inácio Lula da Silva. In. Santos, A; Oliveira, J; Coelho, L. A. Org. (2017). Educação e sua diversidade. Editus.

Gastaldo, D. (2012). Pesquisador/a desconstruído/a e influente? Desafios da articulação teoria-metodologia nos estudos pós-críticos. In: Meyer, D. E; Paraíso, M. E. (2012). Metodologias de pesquisas pós-críticas em educação. Mazza edições.

Hillesheim, L. P. (2018). Contexto de uma educação rejeitada. IN. David, C. Org. (2018). Reflexões e práticas na formação de educadores. EdUERJ.

Holanda, H. B. (2020). Pensamento feminista hoje: perspectivas decoloniais. Bazar do Tempo.

Isobe, R. M; Rezende, V. M. (2019). Percepções dos professores sobre as condições do trabalho docente. IN. Pimenta, J. S. Docência, formação e práticas pedagógicas: experiências e pesquisas. Paco.

Kergoat, D. (2009). Divisão sexual do trabalho e relações sociais do sexo. IN. Hirata, H. Org. (2009) Dicionário crítico do feminismo. Fundação editora da UNESP.

Ludke, M.; André, M. (2013). Pesquisa em educação: abordagens qualitativas. E.P.U.

Lusa, M. G. (2012). Relações de gênero no campo: a superação dos papeis tradicionais como desafio a proteção social básica e o papel dos assistentes sociais. Gênero.

Meyer, D; Paraíso, M. Org. (2012). Metodologia de Pesquisa Pós-Críticas em Educação. Mazza Edições.

Silva, C. (2018). Políticas públicas para educação do campo e formação de professores. IN. ARAÚJO, Gustavo Cunha. Educação do campo, artes e formação docente (Volume 2). Universidade Federal do Tocantins/EDUFT.

Vieira, N. C; Maciel, R. A; Maciel, W. R. (2021). Formação continuada de professores do campo no Programa Escola da Terra e a concepção do currículo. Teias. DOI: 10.12957/teias.2017.27077.

Zanella. A. (2012). Olhar. In. Fonseca, T; Nascimento, N; Maraschin, C. Org. (2012). Pesquisar na diferença: um abecedário. Sulina. 